\title{
GIS BASED CADASTRAL LEVEL FOREST INFORMATION SYSTEM USING WORLD VIEW-II DATA IN BIR HISAR (HARYANA)
}

\author{
K E Mothi Kumar ${ }^{a^{*}}$, Sultan Singha ${ }^{a}$ Priti Attri ${ }^{\mathrm{a}}$, Rupesh Kumar ${ }^{\mathrm{a}}$, Anil Kumara ${ }^{\mathrm{a}}$, Sarika ${ }^{\mathrm{a}}$ and RS Hooda ${ }^{\mathrm{a}}$, \\ ${ }^{a}$ Haryana Space Applications Centre (HARSAC), CCS HAU Campus, Hisar 125004 \\ *kemk@harsac.org \\ and \\ R K Sapra ${ }^{\mathrm{b}}$, Vineet Garg ${ }^{\mathrm{b}}$, Vinod Kumar $^{\mathrm{b}}$ and Nivedita ${ }^{\mathrm{b}}$ \\ ${ }^{\mathrm{b}}$ Haryana Forest Department (HFD), Panchkula
}

KEY WORDS: Cadastral, Forest boundary, Records of Rights (ROR), Ortho-images, Mussavies, Khasra, World View-II

\begin{abstract}
:
Identification and demarcation of Forest lands on the ground remains a major challenge in Forest administration and management. Cadastral forest mapping deals with forestlands boundary delineation and their associated characterization (forest/non forest). The present study is an application of high resolution World View-II data for digitization of Protected Forest boundary at cadastral level with integration of Records of Right (ROR) data. Cadastral vector data was generated by digitization of spatial data using scanned mussavies in ArcGIS environment. Ortho-images were created from World View-II digital stereo data with Universal Transverse Mercator coordinate system with WGS 84 datum.
\end{abstract}

Cadastral vector data of Bir Hisar (Hisar district, Haryana) and adjacent villages was spatially adjusted over ortho-image using ArcGIS software. Edge matching of village boundaries was done with respect to khasra boundaries of individual village. The notified forest grids were identified on ortho-image and grid vector data was extracted from georeferenced cadastral data. Cadastral forest boundary vectors were digitized from ortho-images. Accuracy of cadastral data was checked by comparison of randomly selected geo-coordinates points, tie lines and boundary measurements of randomly selected parcels generated from image data set with that of actual field measurements.

Area comparison was done between cadastral map area, the image map area and RoR area. The area covered under Protected Forest was compared with ROR data and within an accuracy of less than $1 \%$ from ROR area was accepted. The methodology presented in this paper is useful to update the cadastral forest maps. The produced GIS databases and large-scale Forest Maps may serve as a data foundation towards a land register of forests. The study introduces the use of very high resolution satellite data to develop a method for cadastral surveying through on - screen digitization in a less time as compared to the old fashioned cadastral parcel boundaries surveying method.

\section{INTRODUCTION}

Information and monitoring systems for the forest sector are instrumental for effective policies and planning, prioritizing interventions, valuation of forest resources, efficient investment, and engendering accountability. Relevant forest information that is systematically and periodically collected can enable effective implementation of policies, inform decision making, and guide management. The emerging new satellite technologies enabling earth observation at a spatial resolution of $0.6 \mathrm{~m}$ or even $0.41 \mathrm{~m}$ together with powerful and high speed computing and processing capabilities have brought revolutionary changes in the field of GIS-based cadastral land information system. The high-resolution satellite imagery (HRSI) is showing its usefulness for cadastral surveys due to which traditional cadastre and land registration systems have been undergoing major changes worldwide (UN-FIG, 1999).

Land information refers to physical, legal, economic or environmental information or characteristics concerning land, water and sub-surface resources (Holstein, 1990). Land Information System (LIS) is similar to GIS but more focused on land records. GIS and LIS systems provide tools that support many types of records keeping, analysis and decision- making. Land information is an integral part of government, non-profit and private sector activities. The GIS/LIS techniques advance broader social purpose by helping to make more effective decisions for using natural resources in a more optimal way (Barnes, 1990). Land Information System (LIS) consists of spatial and non-spatial data. Both these spatial data (such as parcel boundary, shape, and location) and non-spatial data (such as ownership, rights, and area) are stored, maintained, and accessed in the database environment. Spatial data is acquired through cadastral surveys which are concerned with geometrical data of each land parcel. Cadastral mapping goes a step further and produces complete maps, which are based on cadastral surveys (Steudler, 2004).

The dynamically changing relationship of humankind to land has a great influence on the development of land administration systems (Gopala Rao, 2000). The cadastre is a public record of location, extent, value and ownership of land in a district for the purpose of taxation (Ting and Williamson, 1999). The cadastral system provides an integrated approach to deal with land, law and land owner (Angus, 1989; Dhal, et al,. 1994; Clarissa and Oriando, 1999). The basic elements of the cadastral system include; clear identification of parcel limits, creation of Records of Right (ROR), provision of legal coverage to land owners. The digital cadastral map, the 
fundamental component of cadastral system, is not a map, in the traditional sense. It is neither stored nor it is an image of a geographic area. Instead, the data are stored, from which it is possible to draw a desired view. Although it can be displayed and printed at different scales, projections and colours, it is in fact an analytical tool (Krishna Murthy et al., 1996a; Piotr, 1999; Gopala Rao, 2000).

Cadastral forest mapping deals with forestland boundary delineation through extraction of parcels registered for forest areas and their associated characterization (forest/non-forest) based on the land cover characteristics from high resolution satellite data. Spatial data and information about forestlands are among the most critical in the context of forest and environment protection, spatial planning, monitoring and forest governance.

Forest Information System present an accurate picture of forest lands geographic location and their boundaries, make relevant, reliable, accurate, and up to date spatial forest data and information continuously available to the government, land authorities and communities. It provides consistency in reporting, reduce cost through the sharing of information technology, facilitate citizens, professional, research, and build the land market (Vogiatzis, 2014).

High-resolution space-borne remote sensing image data show a high level of detail and provide many opportunities to be used as base for cadastral map generation. Orthoimage generated by using satellite data having $0.5 \mathrm{~m}$ spatial resolution are ideally suited for deriving cadastral plot vectors for plain areas. The obscured areas need ground survey intervention by DGPS \& ETS (Parida, 2012). Remote Sensing and GIS techniques in forest resource management realizes modern forest space-time adjusting, predicting, decision, inspecting, mapping and evaluating, which provide a scientific foundation for realizing forest resource development and classification management (Muhammad, 2011). The use of GIS technology and web mapping has significantly accelerated the process of Forest mapping and make easy public access, information and participation. The combination of GIS and GPS activities play a crucial role in developing the survey of the forest boundary points and making forest cadastral maps. Area, length other measures in the GIS numerical database are considerably easy (Hulusi, et.al., 2002).

The present study is undertaken to create the digital data base of forest lands in Bir Hissar PF areas. The forest land maps of Bir Hisar P.F. (H.B.No.124), showing the ownership details have been prepared by extraction of land parcels registered for forest areas based on the land cover characteristics from ortho-rectified satellite data.

\section{STUDY AREA}

Hisar is the west central district of Haryana State with a total geographical area of $4050.00 \mathrm{sq}$. km. The study area Bir Hisar is situated in Hisar tehsil, lies between the north latitudes $29^{\circ}$ 07' $23^{\prime \prime}: 29^{\circ} 18^{\prime} 50^{\prime \prime}$ and east longitudes $75^{\circ} 37^{\prime} 31^{\prime \prime}: 75^{\circ} 46^{\prime}$ 34" with 42,692 acres of total geographical area. The district is divided into nine community development blocks namely
Agroha, Adampur, Barwala, Bass (Hansi-II), Hansi-I, Hisar-I, Hisar-II, Narnaund, and Uklana Mandi. The climate of Hisar district can be classified as tropical steppe, semi-arid and hot which is mainly dry with very hot summer and cold winter except during monsoon season when moist air of oceanic origin penetrates into the district. The district area forms a part of Indo-Gangetic plain. The area as a whole is almost flat alluvial plain dotted with sand hummocks and sand dunes. The location of these study areas is shown in Figure 1. The study area comprises of Bir Hisar P.F. (Notification No. S.O. 41/C.A.16/27.S.29/87), Chikanwas P.F. (Notification No. S.O.11/C.A.16/1927/S.29/2014) and Forest Complex P.F. areas (Notification No. S.O.117/C.A.16/1927/S.29/2013).

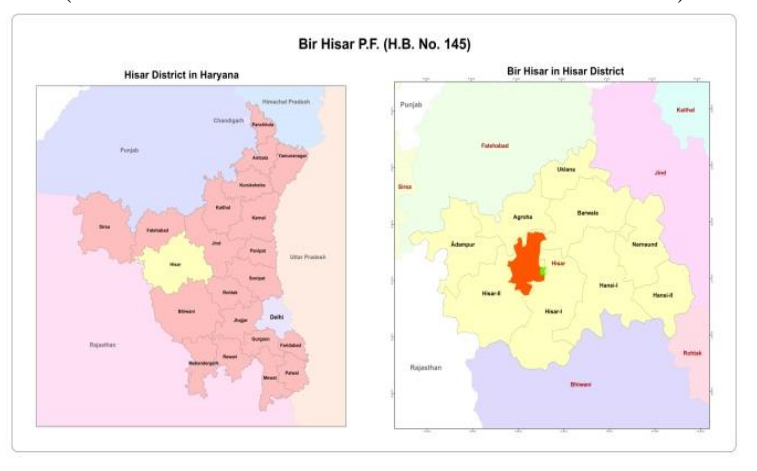

Figure 1. Location of study area.

\section{DATABASE AND METHODOLOGY}

The methodology used in the present study is shown in Figure 2.

\subsection{Data sets used}

(a) Satellite Imagery

High resolution World View-II panchromatic images of 0.50 $\mathrm{m}$ resolution and colored images of $1.86 \mathrm{~m}$ GSD of date 25/01/2011 were acquired for study areas.

(b) Cadastral Map

The mussavies of the study areas were collected from District Revenue Office and used to generate cadastral planimetric vector data. These maps were georeferenced and overlaid on the satellite imagery for further analyses.

(c) Forest Maps

The Forest map of Bir Hisar P.F. provided by Haryana Forest Department was utilized to fix forest boundary and for consideration of min. proportion of some khasra no. within forest land. Min. refers to a portion of khasra (killa) without specific dimensions \& different khasra no.

(d) GPS Data

Garmin GPS navigation receiver was used for GCPs collection.

\subsection{Methodology}

\subsubsection{Ortho-rectification}

Ortho-images were created from World View-II digital stereo data with Universal Transverse Mercator coordinate system with WGS 84 datum. The following inputs were required for the generation of the Ortho-rectified image 
- $\quad$ Digital Satellite Images

- Digital Elevation Model data

- Foot Print Index

- $\quad$ Adjusted Satellite triangulation parameters

- $\quad$ RPC (Rational Polynomial Coefficients) File

- Description and co-ordinates of Primary Control point, Tertiary control Points and Auxiliary control points for connection of vertical control points

Individual scene was Ortho-rectification using the triangulated satellite imageries and DTM as per the defined GSD of sensor. Geometric accuracy of the Ortho was verified by using the available control points. Seam line/cutline was generated along roads, rivers, and streams with ensuring that seem line did not cross important cultural features. Mosaicing and automatic global tone balancing was done. Review of tone balance in the mosaic. Accuracy measurement of orthoimage was done by using check points and control points. Positional accuracy was checked with the help of control points.

\subsubsection{Cadastral vector data generation}

The cadastral maps of the villages collected from the Land Record Department (LRD) were scanned and converted to vector format in ArcGIS environment. Vector cadastral maps were combined with attribute data. Scanning, digitization of Mussavies, updation of digital Mussavies and generation of vector data pertaining to the parcels was done using ArcGIS softwareMussavi refers to mapping sheet consists 16 murraba. Each murrba comprised of 25 killa $(5 \times 5)$. Killa is the smallest land parcel with ownership represented by the positive integer from 1 to 25 in mussavi. Murraba grids (200 karam x 180 karam) and khasra grids (40 karam x 36 karam) were generated. The murrba grid was generated using same origin as that of killa grid in Arc GIS software. The line feature forming murrba grid was converted to polygon feature and the label of each murrba placed at its centroid. Each musavi comprises of the 16 murrba. The features such as village trijunctions, bi-junctions etc. were digitized as point features. The digitization of the features was done as per the dimension specified on the map. The bifurcated / Bata parcels were generated by splitting the killa line boundary as per the distance / dimension specified in the map. Spatial data base was geo-linked by integrated with RoR data and converted into *.shp/*gdb file format. The quality assurance was complying with the positional accuracy, attribute accuracy, logical consistency, completeness and mosaicing fit of the data. Total area of the village by aggregating the parcels, etc. was compared with the area available with the Land Records in the RoRs.

\subsubsection{Field Survey}

Field visits were carried out along with Forest Department officials to locate and draw cadastral forest boundaries using field data and photogrammetric techniques.

\subsubsection{Geo-Referencing of village map}

For geo-referencing the cadastral map, the real world coordinates for sufficient numbers of Ground Control Points
(GCPs) are required. The real world coordinates of the GCP's are obtained through primary sources or secondary sources. The primary sources consists of three modes viz., ground survey, topographical maps and coordinates obtained from GPS (Srinivaso Rao et al., 2003). The secondary sources consist of aerial images or high resolution satellite images.

Sufficient numbers of GCP's were identified on the vector cadastral map, for generating the transform model. The spatial and radiometric resolutions of the satellite data play a major role in identifying the GCP with good geometric definition. GCP's were spread uniformly in the entire map and labelled uniquely for identification in similar coordinate-based survey. Second order polynomial model or affine transformation model was applied for geo-referencing of cadastral map. The transformation model was assessed by the values arrived for residual error at each GCP and root mean square for the entire model. The rms error contribution is less than $3 \mathrm{~m}$ in either direction. The threshold value for the residual error at each GCP is $6 \mathrm{~m}$ in either direction (Srinivaso Rao et al., 2003).

The transformation model was accepted when the actual rms and residual errors arrived is less than the threshold values, and the vector cadastral map is geo-referenced though affine transformation in GIS environment. New vector files were generated for the polygon, line and point features separately. The geo-referenced vector file of each village was validated with reference to the ortho-rectified image. The georeferenced vector file is overlaid on the reference image and initial validation was carried out through visual checking. The displacement was measures as the distance between the image point and the vector point. If the shift was more than allowable limits, geo-referencing was carried out once again. The validation of geo-referenced map, with neighbourhood, using ortho-rectified image was carried out to ensure that the village boundary is matching with all adjoining village boundaries. Due to flat nature of the study area, it was not so difficult to identify respective cadastral boundaries on satellite image.

\subsubsection{Accuracy Checking}

The accuracy of the cadastral maps is analysed through the accuracy of the transformation models, location accuracy and finally the area accuracy of each parcel. The accuracy of digital cadastral maps is assessed through one-to-one matching of the vectorised cadastral maps with the original analog map to ensure the shape and number of the respective parcel and the total number of parcels $\&$ other features in the village, particularly zero labels and duplicate labels and assessment of parcels area in vector layer with respect to the area of parcels mentioned in revenue records.

Accuracy assessment was done by comparison of geocoordinates of randomly selected points generated by computer with that of observed through GPS, comparison of length measurement (of tie lines) generated by computer with that of actual field measurement and comparison of area of randomly selected parcels generated from image data set with that of actual field measurements. Table $1 \&$ Figure 3 (a), (b), (c) \& (d) shows the results of tie-line measurement. Spatial 


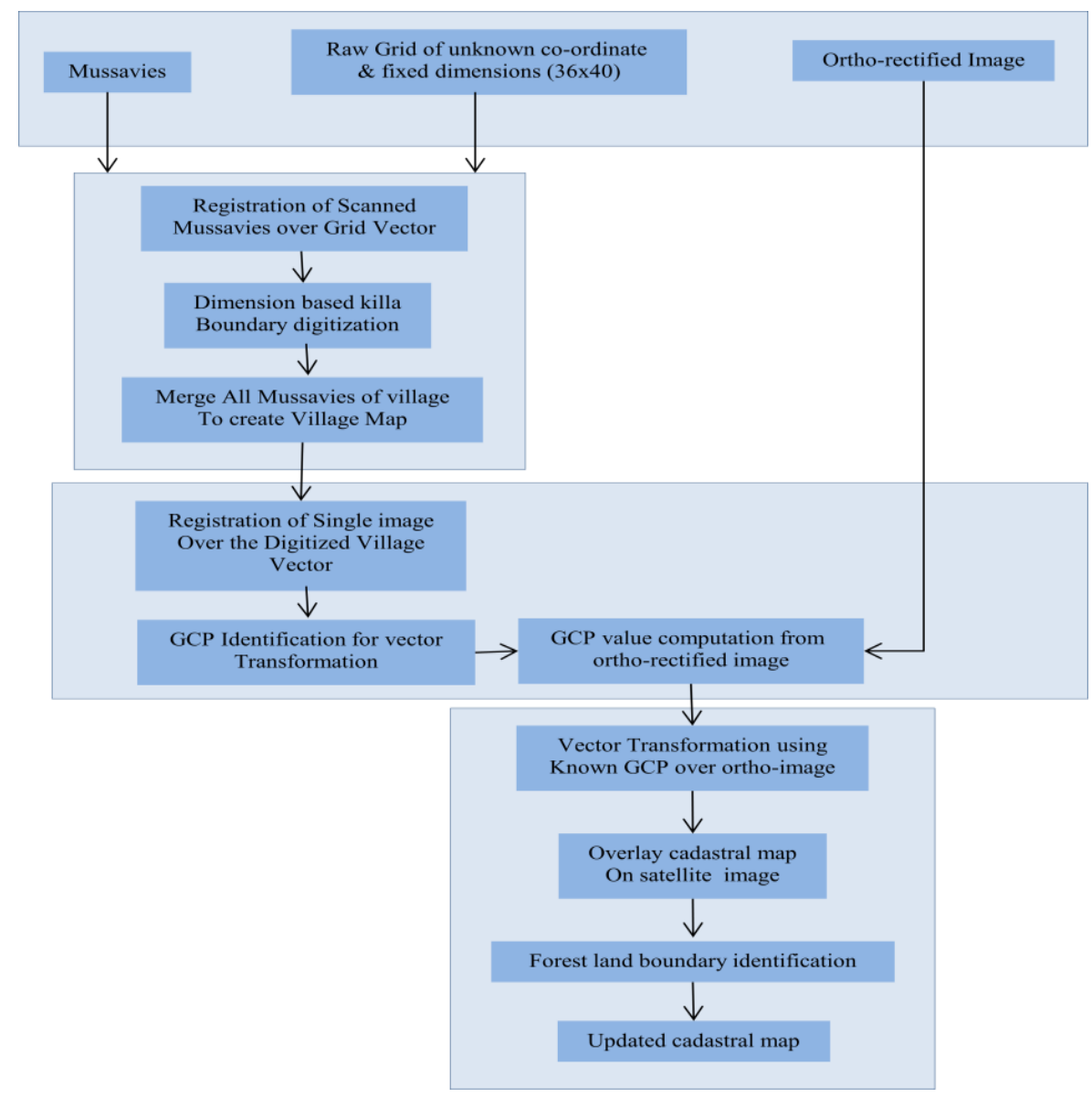

Figure 2. Process Flow of Integrated Approach

adjustment (Transformation) of village vector over the orthorectified high resolution satellite image with length / area accuracy of individual plots / killa not less than $98 \%$ was attained. Edge matching of individual villages was done with accuracy of $98 \%-100 \%$, measured on length / area variations on plots / killa boundaries located at the boundary of Bir Hisar village.
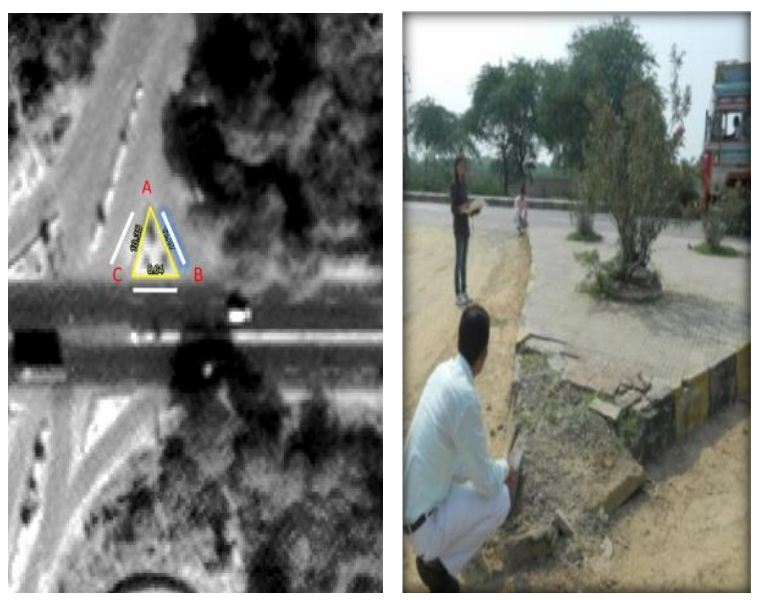

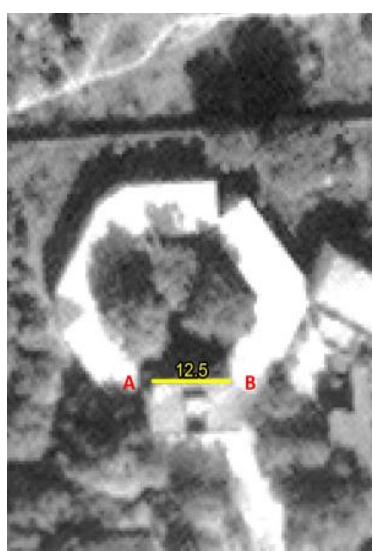

(c)

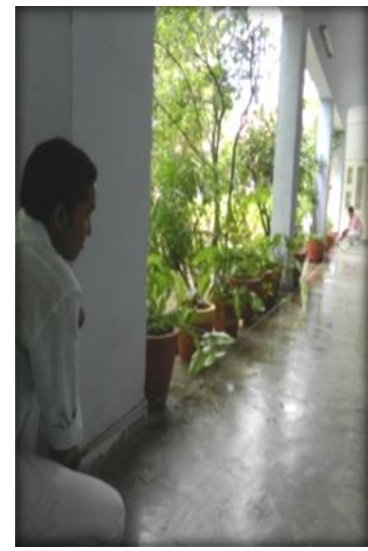

(d)
Figure 3. (a) Tie-line road triangulation points on satellite image, (b) Tie-line measurement points on ground, (c) Tieline Forest Complex points on satellite image, (d) Tie-line measurement points on ground. 
Table 1. Tie-line Measurements

\begin{tabular}{|c|c|c|c|c|c|}
\hline \multirow{2}{*}{$\begin{array}{l}\text { S. } \\
\text { No }\end{array}$} & \multirow[t]{2}{*}{ Area } & \multirow[t]{2}{*}{ Points } & \multicolumn{2}{|c|}{ Distance (mtrs) } & \multirow{2}{*}{$\begin{array}{l}\text { Difference } \\
(\mathrm{mts})\end{array}$} \\
\hline & & & Image & Ground & \\
\hline \multirow[t]{3}{*}{1} & $\begin{array}{l}\text { Bir Hissar } \\
\text { (Nr. Forest } \\
\text { Complex) }\end{array}$ & A-B & 11.7 & 11.6 & 0.1 \\
\hline & & $\mathrm{B}-\mathrm{C}$ & 8.64 & 8.7 & 0.06 \\
\hline & & $\mathrm{C}-\mathrm{A}$ & 10.35 & 10.8 & 0.45 \\
\hline \multirow[t]{4}{*}{2} & $\begin{array}{l}\text { Bir Hissar (Air } \\
\text { Strip) } \\
\end{array}$ & $A-B$ & 30.3 & 30.3 & 0.0 \\
\hline & & $\mathrm{B}-\mathrm{C}$ & 23.41 & 23.9 & 0.49 \\
\hline & & $\mathrm{C}-\mathrm{D}$ & 9.34 & 9.00 & 0.34 \\
\hline & & $\mathrm{D}-\mathrm{A}$ & 24.23 & 24.0 & 0.23 \\
\hline 3 & $\begin{array}{l}\text { Forest Complex } \\
\text { (C F Office) }\end{array}$ & A-B & 12.5 & 12.6 & 0.1 \\
\hline
\end{tabular}

\section{Results and Discussion}

\subsection{Demarcation of Forest land of Bir Hisar P.F.}

Killa / murraba grid number under notified forest land were identified on cadastral map of study area. Separate forest land grid vector layer was prepared from village cadastral map. Forest boundary map of Bir Hisar was scanned and georeferenced using ortho-rectified image. Forest boundary was digitized from that geo-referenced map. Forest land grid vector layer was overlaid on world view image and partitioning of killa grids with min. numbers was done using that digitized forest boundary as reference. Forest area generated from vector layer was compared with total forest area mentioned in notification.

This study introduces an integrated approach for acquiring cadastral data and mapping parcel boundaries by integrating cadastral data, GPS survey and high resolution satellite imagery. Existing cadastral information was acquired from Revenue Office. Mussavies were geo-referenced and mosaiced village-wise including 17 adjoining villages and Bir Hisar. Parcel boundaries were digitized on geo-referenced mussavies using on-screen digitization technique. Villagewise cadastral vector layers were prepared within permissible tolerance limit $\pm 1 \%$ of total area of vector data compared to ROR data. The cadastral layers of Bir Hisar P.F., Chikanwas P.F. and Forest Complex P.F. overlaid on ortho-rectified image are shown in Figure 4, 5 \& 6 .

It was found in the study that high resolution satellite image with a level of detail similar to that obtained by aerial photography, make this technology more suitable for cadastral map generation. The village area from revenue department is collected for the village. The corresponding areas of vector files and geo-referenced files for village area analysis are shown in Table 2. It was observed that in case of Bir Hisar P.F. areas, an area of about 1133.89 acres against the notified area of 1131.29 (2.6 acres difference). In case of Chikanwas P.F. an area of 12.48 acres were calculated against the notified area of 12.50 acres and in case of Forest Complex P.F. an area of 14.40 acres were calculated against the notified area of 14.15 acres ( 0.25 acres of difference). Map. 1 shows final output product, prepared for Bir Hisar P.F. showing the ownership details. The study has revealed that a difference of about 2.6 acres was found to be in Bir Hisar P.F. (1160.74 acres) area from notified forest (1157.94 acres) area.

Table. 2. Comparison of Village vector area with ROR area.

\begin{tabular}{|c|l|c|c|c|}
\hline $\begin{array}{l}\text { S. } \\
\text { No. }\end{array}$ & \multicolumn{1}{|c|}{ Village } & $\begin{array}{l}\text { ROR } \\
\text { area } \\
\text { (Acres) }\end{array}$ & $\begin{array}{l}\text { Geo-referenced } \\
\text { cadastral map area } \\
\text { (Acres) }\end{array}$ & $\begin{array}{l}\text { Difference } \\
\text { (Acres) }\end{array}$ \\
\hline 1. & Bir Hisar P.F. & 1131.29 & 1133.89 & 2.6 \\
\hline 2. & $\begin{array}{l}\text { Chikanwas } \\
\text { P.F. }\end{array}$ & 12.50 & 12.48 & 0.02 \\
\hline 3. & $\begin{array}{l}\text { Forest } \\
\text { Complex P.F. }\end{array}$ & 14.15 & 14.37 & 0.22 \\
\hline
\end{tabular}

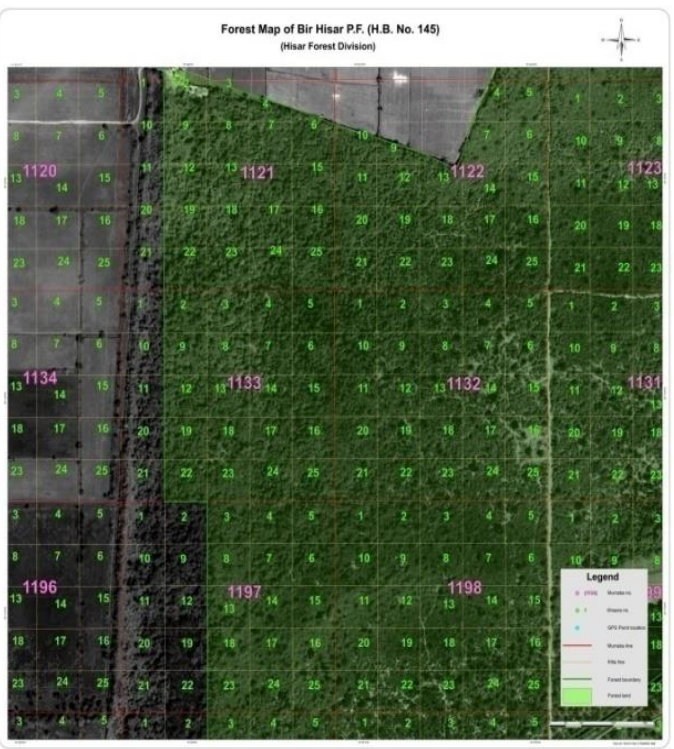

Figure 4. A part of cadastral layer of Bir Hisar (P.F) overlaid on ortho-rectified image.

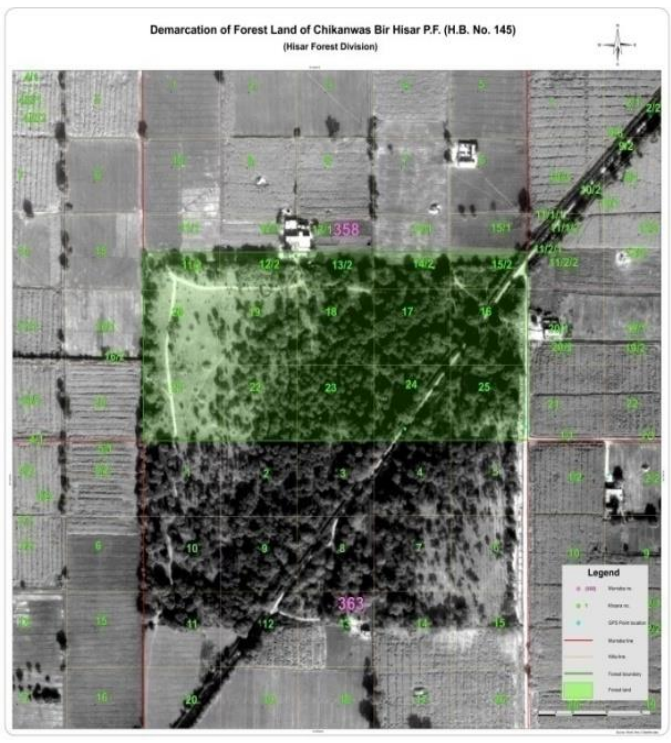

Figure 5. Cadastral layer of Chikanwas P.F. overlaid on orthorectified image. 


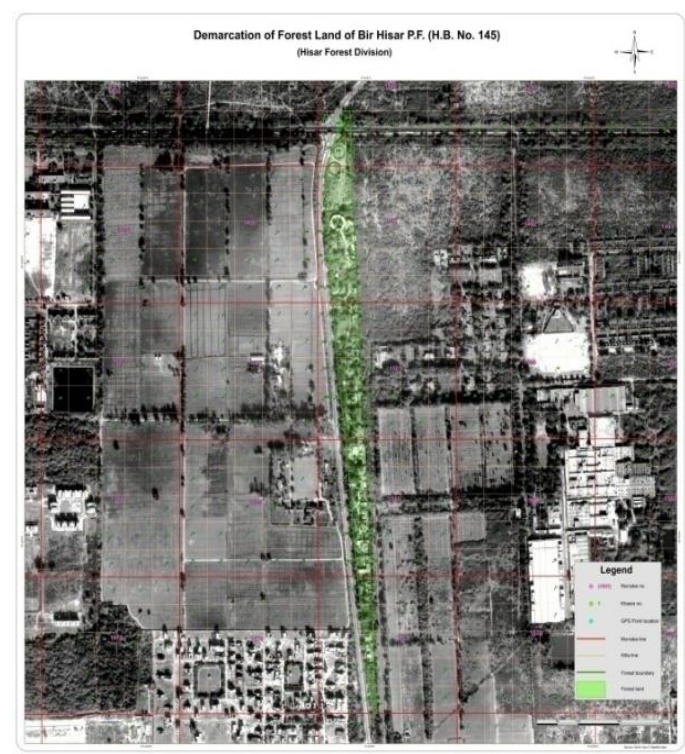

Figure 6. Cadastral layer of Forest Complex P.F. overlaid on ortho-rectified image.

\section{Conclusion}

Forest Information System refers to the process of generating geospatial data, sharing of spatial information about forestlands and their associated resources and management activities, for their sustainable management. The present study was done to prepare the cadastral map of Forest land of Bir Hisar using high resolution satellite data, GPS survey and existing cadastral data. This study illustrates development of geospatial infrastructure for assessment and monitoring of forestlands and their resources to develop transparency in forestland administration that support better decision and policy making.

The accuracy assessment of the cadastral map has been carried out. It is found that area of village vector data is matching with RoR data within $\pm 1 \%$ tolerance limit. Total area of forest land of Bir Hisar (1160.77 acres) having 0.24\% of difference with notified area (1157.94 acres). The present study demonstrates the capability of HRSI data in the demarcation of forest lands at the cadastral level showing the appropriate ownership details.

\section{Acknowledgement}

Authors are thankful to the Chairman, Governing Body HARSAC, Director, HARSAC for allowing us to undertake the study, and to Sh. C R Jotriwal, IFS, PCCF, Haryana Forest Department (HFD), Panchkula for providing necessary funds to carry out the project. The help rendered by all the staff of Forest Department, Hisar is thankfully acknowledged.

\section{References}

Angus-Leppan P.V., 1989. The Thailand Land Titling Project: First Steps in a Parcel Based LIS. Geographical Information Systems, 3(1), pp. 59-68.
Barnes, G., 1990. The evolution of the cadastre concept: From Domesday Book To LIS/GIS network. Surveying and Land Information Journal 50, pp. 5-9.

Clarissa, F. and, Orlando Nino-Fluck, (1999), Cadastre and Land Information Systems for Decision-Makersd in the Developing World. UN-FIG Conference on Land Tenure and Cadastral Infrastructures for Sustainable Development, Melbourne, Australia, 25 - 27 October 1999.

Dhal, N., Madame, R.S. and Krishna Murthy, Y.V.N., 1994. Cadastral Mapping and LIS. Proceedings, 14th INCA Congress, Bangalore.

Gopala Rao, M., 2000. LIS in India- Perspective and Retrospective. Proceedings, National Conference on Land Information System, New Delhi.

Holstein, L.C., 1990. Land Information Management in Support of Urban Development in Developing Countries: Requirements, Issues and Options. Discussion Paper, Infrastructure and Urban Development Department, World Bank.

Hulusi, H., Gumus, S., Yoshimura, T., Gandeseca, S., Topalak, O., Eroglu, H., Eker, M. and Caliskan E., 2002. GPS/GIS Usage on the Forest Boundary Points Surveying and Mapping. International Symposium on GIS, Sept. 23-26, 2002, Istanbul-Turkey.

Krishnamurthy J., Kumar V. N., Jayaraman V and Manivel M., 1996. An approach to demarcate groundwater potential zones through remote sensing and geographic information system. Int. J. Remote Sens. 17, pp. 1867-1884.

Mohammad, 2011. Forest Mapping by Remote Sensing and GIS techniques. Global Journal of Researches in Engineering and Researches in Engineering General Engineering. 11(7), pp. 40-46.

Parida, P.K., Sanabada, M.K., Mohanty, N.D. and Mohapatra A.K., 2012. Cadastral Resurvey using RS, GIS, DGPS \& ETS in Bijepadmanabhapursasana of Digapahandi Tahasil, Ganjam District, Odisha, India. $14^{\text {th }}$ Annual International Conference and Exhibition on Geospatial Information Technology and Applications, 7-9 Feb., 2012.

Piotr C., 1999. Digital Cadastral Maps in Land Information Systems. Liber Quarterly (ISSN 1435-5205), 9(2), pp. 211221.

Srinivasa Rao, S., Krishna Murthy, Y.V.N., Joshi, A.K., Das, S.N., Pandit, D.S., and Shantanu, B., 2003. Computerisation and Geo-referencing of cadastral maps in Chhattisgarh State. Technical Document, Regional Remote Sensing Service Centre/ISRO, Nagpur. 
Steudler, D., 2004. A Framework for the Evaluation of Land Administration Systems. The Department of Geomatics, PhD Thesis, University of Melbourne, Melbourne, Australia, pp. 193.

Ting, L. and Williamson, I.P., 1999. The dynamic humankind-land relationship and its impact on land administration systems. Proceedings of the joint United Nations and FIG International Conference on Land Tenure and Cadastral Infrastructures for Sustainable Development, Melbourne, 24-27 October, 1999.
UN-FIG, 1999. Bathurst declaration on land administration for sustainable development. In: The International Federation of Surveyors (FIG). Bathurst, Australia. Copenhagen. $18^{\text {th }}$ and $22^{\text {nd }}$ October 1999.

Vogiatzis, M., 2014. A Forest land Information System in support of sustainable management and use of forests. IUFRO World Congress, Salt Lake City, Utah, USA. 


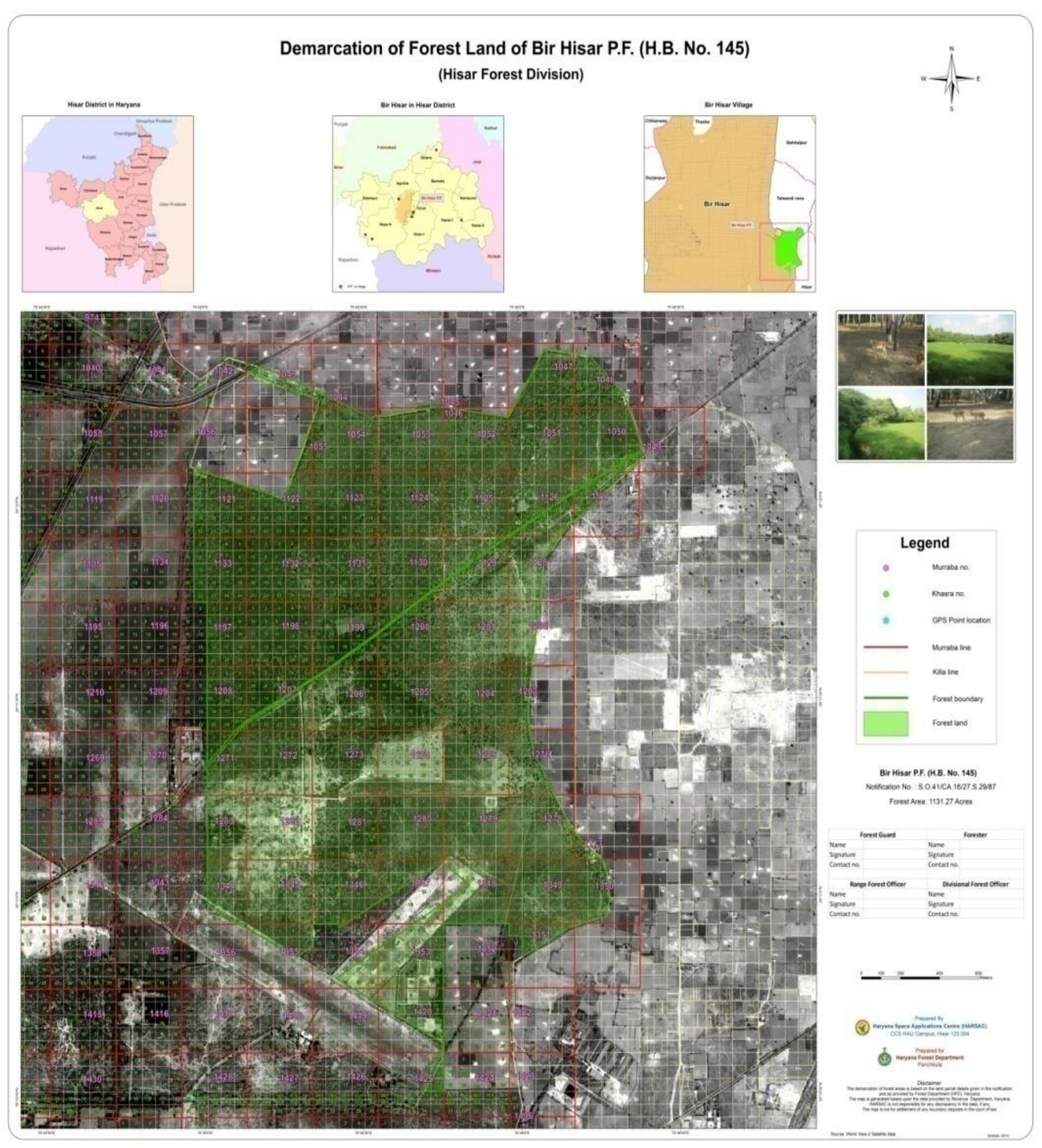

Map 1 